\title{
Avaliação do Programa de Excelência Gerencial: a Percepção dos Militares do Corpo Permanente da Escola Preparatória de Cadetes do Exército Brasileiro
}

\author{
Rogério da Silva Nunes ${ }^{1}$ \\ Mauro Stopatto ${ }^{2}$ \\ Marcos Baptista Lopez Dalmau ${ }^{3}$ \\ Mário de Souza Almeida ${ }^{4}$
}

\section{Resumo}

Este trabalho procura discutir a implementação do Programa de Excelência Gerencial do Exército Brasileiro (PEG-EB) na Escola Preparatória de Cadetes do Exército (EsPCEx), identificar a importância do programa e mostrar a percepção dessa implantação pelo corpo permanente de oficiais e praças. Os militares apresentaram sua percepção em relação ao programa e sua implantação através dos sete critérios da qualidade do Programa de Qualidade do Governo Federal (PQGF). O trabalho caracteriza a organização pesquisada: missão, visão de futuro, síntese dos valores, deveres, ética e os principais aspectos da evolução da estrutura organizacional. Foi aplicado um instrumento de pesquisa com 53 assertivas, referentes aos critérios adotados pelo PEG-EB, em 175 militares pertencentes ao quadro complementar de Oficiais (QCO) e o Serviço Técnico Temporário (STT) da EsPCEx, com uma escala do tipo Likert, graduada de zero a quatro. Os resultados foram tabulados com técnicas de análise multivariada, realizada através de um pacote estatístico (SPSS) e mostra a percepção dos participantes do programa de qualidade em relação a cada um dos critérios adotados pelo PEG-EB.

Palavras-chave: Avaliação de gestão. Programa de excelência gerencial. Escola de preparatória de cadetes do exército brasileiro.

\footnotetext{
${ }^{1}$ Doutorado em Administração pela Universidade de São Paulo. Professor Adjunto da Universidade Federal de Santa Catarina. Endereço: Universidade Federal de Santa Catarina, Centro Sócio Econômico, Campus Universitário Prof. João David Ferreira Lima, s/n, Trindade, CEP: $88040-900$ Florianópolis, SC-Brasil.E-mail: rogeriosnunes@hotmail.com.

${ }^{2}$ Mestrado em Administração de Empresas pela Faculdade de Ciências Econômicas de São Paulo. Coordenador do Curso de Administração da Faculdade Politécnica de Sumaré. Escola Preparatória de Cadetes do Exército. Endereço: Grupo Polis Educacional, Policamp Sumaré, Coordenador do Curso de Administração, Praça da Republica n. 72, Centro, CEP: 13170-003 -Sumaré, SP -Brasil.E-mail:maurostopatto@gmail.com.

${ }^{3}$ Professor adjunto III do Depto. de Administração da UFSC. Doutorado em Engenharia de Produção pela Universidade Federal de Santa Catarina. Pesquisador da Universidade Federal de Santa Catarina. Endereço: Universidade Federal de Santa Catarina, CAD - CSE, Campus Universitário, Trindade, CEP: 88040-900-Florianópolis, SC-Brasil.E-mail: dalmau@cse.ufsc.br.

${ }^{4}$ Doutorado em Engenharia de Produção pela Universidade Federal de Santa Catarina. Professor do Magistério Superior da Universidade Federal de Santa Catarina. Endereço: Universidade Federal de Santa Catarina, CAD-CSE, Campus Universitário, Trindade, CEP: 88040-900-Florianópolis, SC-Brasil.E-mail: almeida@cse.ufsc.br.

Artigo recebido em: 07/05/2010. Aceito em: 13/07/2010. Membro do Corpo Editorial Científico responsável pelo processo editorial: Thomas G. Brashear.
} 


\section{Introdução}

O Programa de Excelência Gerencial do Exército Brasileiro (PEG-EB) é o instrumento de implementação da estratégia de reorganização das atividades internas sob a égide da excelência, estabelecida pela Portaria do Comandante do Exército n. 191, de 17 de abril de 2003.

Esse modelo foi desenvolvido nos Estados Unidos, após um estudo feito em grandes empresas que apresentavam desempenho superior, chamado também de Organizações de Classe Mundial. No Brasil, passou a ser difundido no início da década de 1990, pela Fundação para o Prêmio Nacional da Qualidade (FPNQ), e, recentemente, pelo Ministério do Planejamento, por meio do Programa da Qualidade no Serviço Público (PQSP). Todas as organizações militares aderiram ao PEG-EB e vêm desenvolvendo ações que visam ao aperfeiçoamento $e$ à modernização de seus sistemas de gerenciamento (ROBBI, 2004).

O trabalho procura discutir a percepção dos militares da Escola Preparatória de Cadetes do Exército (EsPCEx), com relação ao Programa de Excelência Gerencial do Exército Brasileiro (PEG-EB), bem como identificar e analisar as consequências administrativas implementadas através do programa na EsPCEx. O artigo apresenta os principais projetos, estratégias e instrumentos de gestão disponíveis para a Administração Pública, como o programa de Excelência Gerencial do Exército Brasileiro (PEG-EB) e o Prêmio Nacional da Gestão Pública do Governo Federal (BRASIL, 2004), também procura apresentar como foi implantado o Programa de Excelência Gerencial do Exército Brasileiro (PEG-EB) no âmbito Escola Preparatória de Cadetes do Exército (EsPCEx) e verificar os benefícios advindos da adoção do modelo gerencial implantado pelo Programa de Excelência Gerencial.

A Escola Preparatória de Cadetes do Exército (EsPCEx) é o único acesso à carreira de oficial combatente do Exército Brasileiro. Portanto, os egressos da EsPCEx serão os únicos a ascenderem ao posto máximo do Exército Brasileiro, o de General de Exército. Por esse motivo a Escola Preparatória de Cadetes do Exército assume grande relevância estratégica para o Exército e consequentemente para o Programa de Excelência Gerencial do Exército (PEG-EB).

Anualmente, através de um concurso público do âmbito nacional para preenchimento de aproximadamente 500 vagas, a EsPCEx realiza a seleção de jovens que aspiram às carreiras de oficial combatente do Exército Brasi- 
leiro. Ao término de um ano de estudos, o aluno aprovado recebe os Certificados de Conclusão do ensino médio e de Reservista de segunda Categoria, e, ainda, conquista o direito de ingressar na Academia Militar das Agulhas Negras, onde estudará por mais quatro anos, para depois ser promovido ao posto de Aspirante a Oficial do Exército.

O trabalho visa medir a percepção dos Oficiais e Praças do corpo permanente da EsPCEx, em relação à implantação do Programa de Excelência Gerencial (PEG-EB); descrever o Programa de Excelência Gerencial do Exército Brasileiro (PEG-EB) na Escola Preparatória de Cadetes de Exército (EsPCEx); e verificar os benefícios advindos da adoção do modelo gerencial implantado pelo Programa de Excelência Gerencial (PEG).

Pela relevância estratégica do Exército para o país, um estudo de caso sobre seu Programa de Excelência Gerencial (PEG) na Escola Preparatória de Cadetes de Exército (EsPCEx) assume grande importância, uma vez que a metodologia aplicada ao estudo em questão é o estudo de caso, definido, conforme Yin (2005, p. 32), como

Um estudo de caso é uma investigação empírica que investiga um fenômeno contemporâneo dentro de seu contexto da vida real, especialmente quando os limites entre o fenômeno e o contexto não estão claramente definidos.

\section{A Avaliação Continuada da Gestão Pública}

De acordo com Brasil (2004), o modelo parte do diagnóstico de que o maior desafio do setor público brasileiro é de natureza gerencial. Assim, na década de 1990, buscou-se um novo modelo de Gestão Pública focado em resultados e orientado para o cidadão.

Esse modelo de Gestão Pública deveria orientar as organizações nessa transformação gerencial e, ao mesmo tempo, permitir avaliações comparativas de desempenho entre organizações públicas brasileiras e estrangeiras $e$ mesmo com empresas e demais organizações do setor privado.

Em 1997, foram introduzidos os Critérios de Excelência, cujos fundamentos representam o "estado da arte" em gestão. O Modelo de Excelência em Gestão Pública é a representação de um sistema gerencial que se constitui em sete partes integradas que orientam a adoção de práticas de excelên- 
cia em gestão com a finalidade de levar as organizações públicas brasileiras a padrões elevados de desempenho e de excelência em gestão, organizadas nos seguintes blocos:

a) Liderança, estratégias e planos e cidadãos e sociedade - forma o que pode ser denominado de planejamento. Por meio da liderança forte da alta administração, que focaliza as necessidades dos cidadãos destinatários da ação da organização, os serviços/produtos e os processos são planejados para melhor atender esse conjunto de necessidades, levando em conta os recursos disponíveis.

b) Pessoas e processos - representa a execução do planejamento. Nesse espaço se concretiza a ação que transforma os objetivos e as metas em resultados. São as pessoas, capacitadas e motivadas, que operam esses processos e fazem com que cada um deles produza os resultados esperados.

c) Resultados - representa o controle, pois serve para acompanhar o atendimento à satisfação dos destinatários, dos serviços e da ação do Estado, o orçamento e as finanças, a gestão das pessoas, a gestão de fornecedores e das parcerias institucionais, bem como o desempenho dos serviços/produtos e dos processos organizacionais.

d) Informação - representa a "inteligência da organização", nesse bloco são processados e avaliados os dados e fatos da organização (internos), e aqueles provenientes do ambiente (externos) que não estão sob seu controle direto, mas que de alguma forma podem influenciar no seu desempenho. Este bloco dá à organização a capacidade de agir corretivamente ou ajuda a melhorar as suas práticas de gestão e, consequentemente, seu desempenho.

Para efeito de avaliação da gestão, as sete partes do Modelo de Excelência em Gestão Pública foram transformadas em Critérios de avaliação. Conforme pode ser observado na Figura 1: 


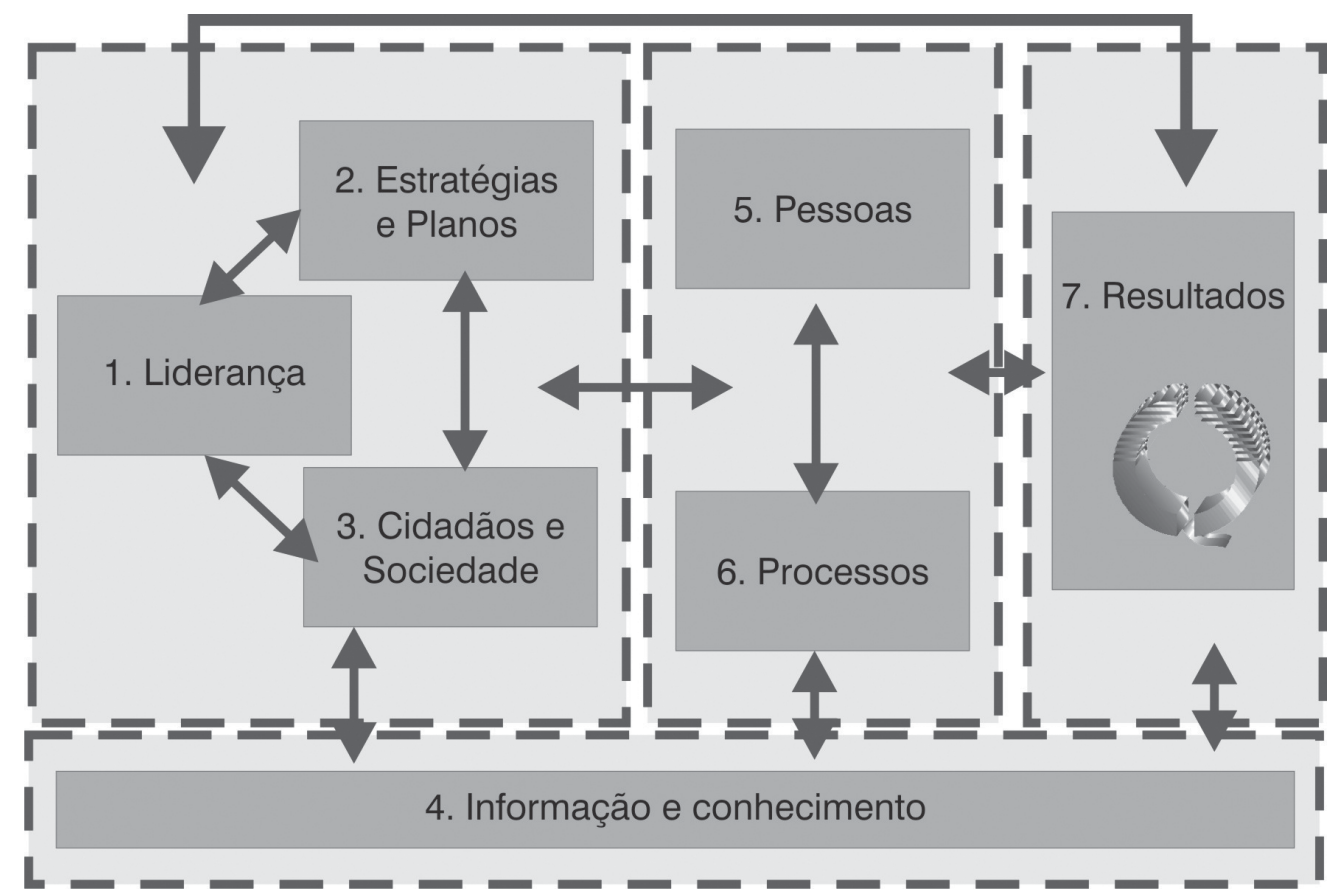

Figura 1: Modelo de Excelência em Gestão Publica Fonte: Brasil (2004, p. 21)

Cabe a cada organização definir, em seu plano de melhoria de gestão, o que fazer para responder às oportunidades de melhorias identificadas durante a avaliação. No entanto, os critérios estabelecem de forma prescritiva o que se espera de uma Gestão Pública de excelência. Esses princípios e características de uma gestão de excelência constituem o centro do processo de avaliação e devem ser evidenciados pelas práticas de gestão da organização e pelos resultados decorrentes dessas práticas.

O Sistema de Avaliação Continuada da Gestão Pública é um conjunto integrado de ações, realizadas de modo contínuo, que se inicia com a decisão da organização de avaliar continuamente as práticas e os resultados da sua gestão e se mantém ao longo do tempo mediante repetição cíclica do processo (BRASIL, 2008).

A avaliação continuada da gestão, em cada ciclo, compreende as ações identificadas na Figura 2: 


\section{Sistema de avaliação continuada da Gestão Pública: fases de um ciclo}

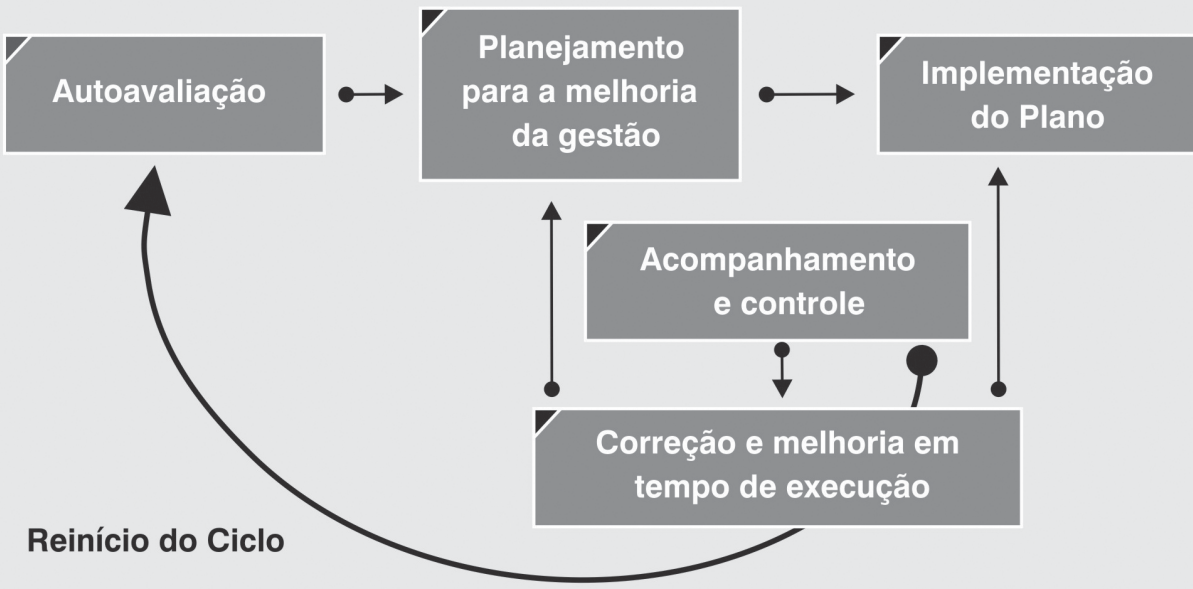

Figura 2: As fases de um ciclo no Sistema de Avaliação Continuada da Gestão Pública Fonte: Brasil (2008, p. 22)

Segundo Brasil (2008), a autoavaliação é um diagnóstico interno, feito pela própria organização, tendo por objetivo quantificar e qualificar os principais fatores relacionados à organização, com ênfase em suas práticas de gestão e resultados institucionais, com o propósito de transferir o conhecimento em avaliação da gestão e criar um ambiente de autoavaliação sem a presença de pessoas que não pertencem aos quadros da organização.

O Manual para Avaliação da Gestão Pública está estruturado em sete critérios, correspondentes às sete partes do Modelo de Excelência em Gestão Pública, desdobrados em itens de avaliação, conforme pode ser observado no Quadro 1:

\section{CRITÉRIOS E ITENS}

\section{Liderança}

1.1 Sistema de liderança

1.2 Cultura da excelência

1.3 Análise do desempenho global

\section{Estratégias e planos}

2.1 Formulação das estratégias

2.2 Desdobramento e formulação de estratégias

2.3 Formulação do sistema de avaliação de desempenho 


\section{CRITÉRIOS E ITENS}

\section{Cidadãos e sociedade}

3.1 Imagem e conhecimento mútuo

3.2 Relacionamento com os cidadãos-usuários

3.3 Interação com a sociedade

\section{Informações e conhecimento}

4.1 Gestão das informações da organização

4.2 Gestão das informações comparativas

4.3 Gestão do capital intelectual

\section{Pessoas}

5.1 Sistemas de trabalho

5.2 Educação e capacitação

5.3 Qualidade de vida

\section{Processos}

6.1 Gestão de processos finalísticos

6.2 Gestão de processos de apoio

6.3 Gestão de processos de suprimentos

6.4 Gestão orçamentária e financeira

\section{Resultados}

7.1 Resultados relativos aos cidadãos-usuários e à sociedade

7.2 Resultados orçamentários e financeiros

7.3 Resultados relativos às pessoas

7.4 Resultados relativos a suprimento

7.5 Resultados relativos aos serviços e produtos

7.6 Resultados dos processos de apoio e organizacional

Quadro 1: Critérios e itens do Manual para Avaliação da Gestão Pública Fonte: Adaptado de Brasil (2008)

Para Brasil (2004), uma das características da gestão de excelência é a técnica de controle e de melhoria das próprias práticas de gestão da organização. A organização pode realizar o controle periódico dessas práticas, interferindo, corretivamente, sempre que for necessário. 


\section{Aspectos Metodológicos}

A população pesquisada é composta pelos integrantes do corpo permanente dos militares, oficiais, subtenentes e sargentos, da EsPCEx. A população é composta por 175 membros do efetivo permanente de militares, formados pelos 118 oficiais compreendidos entre os postos de segundo tenente e coronel, e por 57 subtenentes e sargentos compreendidos entre graduações de terceiro sargento e subtenente.

Para chegar a essa população foram excluídos os alunos, uma vez que permanecem por apenas nove meses e não acompanharam o processo de implantação do Programa de Excelência Gerencial (PEG) nos últimos anos. Pelo mesmo motivo, também foram excluídos os 134 recrutas. Foram retirados, ainda, os 49 servidores civis, pois o objetivo é analisar a percepção dos militares no corpo permanente em relação ao Programa de Excelência Gerencial (PEG-B).

Os 175 membros da pesquisa estão compreendidos entre o comando, os integrantes da alta administração correspondente ao Estado maior da Unidade Militar, sendo, portanto, a assessoria direta do Comandante da Unidade Administrativa, equivalente aos membros do colegiado em uma organização civil.

Os dados foram tabulados, tratados e interpretados utilizando como suporte o aplicativo Statistical Package for Social Sciences (SPSS) versão 10.0. $\mathrm{O}$ instrumento de coleta de dados é um questionário fechado e composto por 53 assertivas classificadas em uma escala de Likert, com os valores variando de forma escalonada entre 0 e 4.

As oito primeiras assertivas do instrumento referem-se ao critério de liderança, as de nove a 14 para as de estratégias e planos, de 15 a 21 cidadão e sociedade, de 22 a 28 informação e conhecimento, de 29 a 36 pessoas, de 37 a 44 processos e as de 45 a 53 resultados, conforme mostra o Quadro 2: 


\begin{tabular}{|c|c|c|}
\hline \multicolumn{2}{|r|}{ Assertivas } & Critério \\
\hline 1 & $\begin{array}{l}\text { As decisões tomadas pela alta administração são comunicadas para } \\
\text { as partes interessadas pertinentes. }\end{array}$ & \multirow{8}{*}{ Liderança } \\
\hline 2 & $\begin{array}{l}\text { As implantações das ações decorrentes destas decisões são acompa- } \\
\text { nhadas pela alta administração. }\end{array}$ & \\
\hline 3 & $\begin{array}{l}\text { A alta administração atua pessoalmente para garantir recursos para a } \\
\text { infraestrutura. }\end{array}$ & \\
\hline 4 & $\begin{array}{l}\text { Os valores e as diretrizes da administração pública são disseminados } \\
\text { e internalizados na organização. }\end{array}$ & \\
\hline 5 & $\begin{array}{l}\text { As avaliações dos padrões de trabalho relativos às culturas da exce- } \\
\text { lência são feitas. }\end{array}$ & \\
\hline 6 & $\begin{array}{l}\text { As implantações de inovações ou melhorias das práticas de gestão } \\
\text { são feitas. }\end{array}$ & \\
\hline 7 & $\begin{array}{l}\text { O desempenho global da organização é analisado criticamente em } \\
\text { relação às estratégias e planos de ação. }\end{array}$ & \\
\hline 8 & $\begin{array}{l}\text { O desempenho global da organização é analisado considerando as } \\
\text { necessidades de todas as partes interessadas. }\end{array}$ & \\
\hline 9 & $\begin{array}{l}\text { A organização participa da formulação das políticas públicas em sua } \\
\text { área de atuação. }\end{array}$ & \multirow{5}{*}{$\begin{array}{l}\text { Estratégias e } \\
\text { planos }\end{array}$} \\
\hline 11 & $\begin{array}{l}\text { As estratégias são desdobradas em planos de ação, para os diversos } \\
\text { setores e unidades da organização. }\end{array}$ & \\
\hline 12 & $\begin{array}{l}\text { Os recursos alocados são suficientes para assegurar a implantação de } \\
\text { todos os planos de ação estabelecidos. }\end{array}$ & \\
\hline 13 & $\begin{array}{l}\text { Existem sistemas de medição que monitore o desempenho da im- } \\
\text { plantação das estratégias em todos os níveis da organização. }\end{array}$ & \\
\hline 14 & $\begin{array}{l}\text { Os indicadores de desempenho e as metas estratégicas são adequa- } \\
\text { dos e previamente comunicados às partes interessadas. }\end{array}$ & \\
\hline 15 & $\begin{array}{l}\text { A organização costuma identificar os seus cidadãos-usuários atuais e } \\
\text { potenciais e os classificá-los por tipos ou grupos. }\end{array}$ & \multirow{6}{*}{$\begin{array}{l}\text { Cidadãos e } \\
\text { sociedade }\end{array}$} \\
\hline 16 & $\begin{array}{l}\text { A organização divulga seus serviços e ações aos seus usuários atuais } \\
\text { e potenciais e à sociedade. }\end{array}$ & \\
\hline 17 & São disponibilizados canais de acesso para solicitar assistência. & \\
\hline 18 & São disponibilizados canais de acesso para solicitar esclarecimentos & \\
\hline 19 & São disponibilizados canais de acesso para sugestões e reclamações. & \\
\hline 20 & $\begin{array}{l}\text { A organização divulga padrões de qualidade no atendimento aos } \\
\text { usuários de seus serviços. }\end{array}$ & \\
\hline
\end{tabular}

Quadro 2: Instrumento de coleta de dados

Fonte: Elaborado pelos autores 


\begin{tabular}{|c|c|c|}
\hline \multicolumn{2}{|r|}{ Assertivas } & Critério \\
\hline 21 & $\begin{array}{l}\text { A organização orienta e estimula a sociedade a controlar seus resulta- } \\
\text { dos institucionais. }\end{array}$ & $\begin{array}{l}\text { Cidadãos e } \\
\text { sociedade }\end{array}$ \\
\hline 22 & $\begin{array}{l}\text { A organização promove a responsabilidade pública das pessoas no } \\
\text { cumprimento de seu papel de agente público, estimulando os valores } \\
\text { e o comportamento ético. }\end{array}$ & \multirow{7}{*}{$\begin{array}{l}\text { Informação e } \\
\text { conhecimento }\end{array}$} \\
\hline 23 & $\begin{array}{l}\text { As principais informações da organização são obtidas levando-se em } \\
\text { conta as necessidades de seus usuários. }\end{array}$ & \\
\hline 24 & $\begin{array}{l}\text { As informações são disponibilizadas aos seus usuários com acesso } \\
\text { rápido e fácil. }\end{array}$ & \\
\hline 25 & $\begin{array}{l}\text { A organização define e prioriza as informações comparativas de que } \\
\text { necessita. }\end{array}$ & \\
\hline 26 & $\begin{array}{l}\text { A organização assegura que o conhecimento esteja alinhado com } \\
\text { suas estratégias e seja compartilhado. }\end{array}$ & \\
\hline 27 & $\begin{array}{l}\text { É feita a avaliação da implementação de inovações ou melhorias das } \\
\text { práticas de gestão. }\end{array}$ & \\
\hline 28 & $\begin{array}{l}\text { É feita a avaliação dos padrões de trabalho relativos à gestão das } \\
\text { informações. }\end{array}$ & \\
\hline 29 & $\begin{array}{l}\text { A organização assegura que a gestão do conhecimento seja utilizada } \\
\text { para melhorar seus produtos e serviços. }\end{array}$ & \multirow{8}{*}{ Pessoas } \\
\hline 30 & Os canais de interlocução e negociação estão definidos e pertinentes. & \\
\hline 31 & $\begin{array}{l}\text { Os cargos e funções são preenchidos de acordo com as características } \\
\text { e habilidades necessárias. }\end{array}$ & \\
\hline 32 & $\begin{array}{l}\text { As necessidades de educação e capacitação são identificadas e defini- } \\
\text { das considerando as estratégias da organização. }\end{array}$ & \\
\hline 33 & $\begin{array}{l}\text { As necessidades de educação e capacitação são identificadas e defini- } \\
\text { das considerando a melhoria do desempenho das pessoas. }\end{array}$ & \\
\hline 34 & $\begin{array}{l}\text { As necessidades de educação e capacitação são identificadas e defini- } \\
\text { das considerando o crescimento individual das pessoas. }\end{array}$ & \\
\hline 35 & $\begin{array}{l}\text { O orçamento existente para os planos de educação e capacitação é } \\
\text { adequado. }\end{array}$ & \\
\hline 36 & $\begin{array}{l}\text { O ambiente organizacional é seguro e saudável, considerando-se a } \\
\text { ergonomia, saúde e bem-estar das pessoas. }\end{array}$ & \\
\hline
\end{tabular}

Quadro 2: Instrumento de coleta de dados

Fonte: Elaborado pelos autores 


\begin{tabular}{|c|c|c|}
\hline \multicolumn{2}{|r|}{ Assertivas } & Critério \\
\hline 37 & $\begin{array}{l}\text { A organização mede e avalia o bem estar, a satisfação e a motivação } \\
\text { das pessoas. }\end{array}$ & \multirow{6}{*}{ Processos } \\
\hline 38 & $\begin{array}{l}\text { Os custos associados aos projetos finalísticos são otimizados e com- } \\
\text { patíveis às necessidades. }\end{array}$ & \\
\hline 39 & $\begin{array}{l}\text { É feita a avaliação da implementação de melhorias das práticas de } \\
\text { gestão. }\end{array}$ & \\
\hline 42 & $\begin{array}{l}\text { O processo de compras de bens materiais e de serviços é realizado } \\
\text { levando-se em consideração as necessidades internas da organização. }\end{array}$ & \\
\hline 43 & $\begin{array}{l}\text { A gestão orçamentária e financeira é utilizada para suportar as estraté- } \\
\text { gias e os planos da organização. }\end{array}$ & \\
\hline 44 & $\begin{array}{l}\text { As operações da organização são acompanhadas em termos orça- } \\
\text { mentários e financeiros. }\end{array}$ & \\
\hline 45 & Os indicadores de satisfação dos usuários são mensurados e analisados. & \multirow{9}{*}{ Resultados } \\
\hline 46 & $\begin{array}{l}\text { Os indicadores relativos à interação com a sociedade são mensurados } \\
\text { e analisados. }\end{array}$ & \\
\hline 47 & $\begin{array}{l}\text { São utilizados indicadores de aplicação dos recursos orçamentários e } \\
\text { financeiros. }\end{array}$ & \\
\hline 48 & $\begin{array}{l}\text { São utilizados indicadores relativos à conservação do patrimônio e } \\
\text { arrecadação de receitas. }\end{array}$ & \\
\hline 49 & Os indicadores evidenciam melhorias nos sistemas de trabalho. & \\
\hline 50 & $\begin{array}{l}\text { Existem indicadores evidenciando decréscimo no bem-estar e satisfa- } \\
\text { ção das pessoas. }\end{array}$ & \\
\hline 51 & Os indicadores evidenciam melhorias no processo de suprimentos. & \\
\hline 52 & Os indicadores evidenciam decréscimo nos serviços e produtos. & \\
\hline 53 & Os indicadores evidenciam melhorias nas práticas de gestão. & \\
\hline
\end{tabular}

Quadro 2: Instrumento de coleta de dados

Fonte: Elaborado pelos autores

Foi testada a normalidade dos dados, através do teste de normalidade Kolmogorov-Smirnov e pelo índice de assimetria de Pearson. Toledo e Ovalle (1987, p. 249) esclarecem que "assimetria significa desvio ou afastamento da simetria, é o grau de deformação de uma curva”. Portanto, uma curva simétrica é aquela cujos valores das medidas de tendência central são iguais, ou seja, média, moda e mediana têm os mesmos valores e, nesse caso, o índice de assimetria de Pearson será igual a zero e teremos uma distribuição 
com aderência $100 \%$ à distribuição normal. Caso a média seja superior à mediana e à moda, teremos uma curva assimétrica à direita com deformação positiva e no caso da média ter valor inferior à mediana e à moda, teremos uma curva de frequências assimétricas à esquerda com deformação negativa. Os dados foram tabulados no aplicativo SPSS de acordo com o número total de respondentes.

\section{Resultados}

Os Oficiais e Praças do corpo permanente da EsPCEx expressaram através das 53 assertivas sua percepção em relação à implantação do Programa de Excelência Gerencial (PEG-EB). Essa percepção foi externada pelo corpo permanente, uma vez que os critérios de excelência analisados nos relatórios de autoavaliação foram expostos no instrumento.

Para analisar a consistência ou confiabilidade interna dos dados e com isso ter a certeza de que as variáveis que foram medidas conseguiram estar isentas de viés, foi calculado teste Alfa de Cronback com o uso do SPSS. A correlação média interitens foi calculada em 0,9483.

Foi testada também a normalidade dos dados, através do teste de normalidade Kolmogorov-Smirnov que apresentou significância inferior a 0,05 para todas as variáveis. Os cálculos dos testes de normalidade com suas significâncias para cada variável. Para todas assertivas foram calculados os índices de assimetria de Pearson, média, mediana e moda.

Para analisar a consistência ou confiabilidade interna dos dados e com isso se ter à certeza de que as variáveis que foram medidas conseguiram estar isentas de viés, foi calculado teste Alfa de Cronback com o uso do SPSS. A correlação média inter-itens foi alta, pois o alfa foi bastante elevado igual a 0,9483 . Como teste, Alfa de Cronback apresentou valor muito alto existe a evidência de que os itens estão medindo a mesma construção subjacente. (PETERSON, 1994).

Foi testada também a normalidade dos dados, através do teste de normalidade Kolmogorov-Smirnov que apresentou significância inferior a 0,05 para todas as variáveis e todos os respondentes, logo de acordo com esse teste as distribuições das variáveis não encontram aderência à curva normal, os cálculos dos testes de normalidade com suas significâncias para cada variável. 
$\mathrm{Na}$ análise da assimetria para as assertivas estudadas observou-se que a algumas apresentaram baixíssimos índices de assimetria, igual ou menor a 0,15, aproximando-se bastante de uma distribuição $100 \%$ simétrica ou normal (índice de assimetria igual a zero). São elas, de acordo com o Quadro 3:

\begin{tabular}{|c|c|}
\hline \multicolumn{2}{|r|}{ Assertivas } \\
\hline 5 & As avaliações dos padrões de trabalho relativos às culturas da excelência são feitas. \\
\hline 7 & $\begin{array}{l}\text { O desempenho global da organização é analisado criticamente em relação às estratégias } \\
\text { e planos de ação. }\end{array}$ \\
\hline 13 & $\begin{array}{l}\text { Existem sistemas de medição que monitore o desempenho da implantação das estraté- } \\
\text { gias em todos os níveis da organização. }\end{array}$ \\
\hline 15 & $\begin{array}{l}\text { A organização costuma identificar os seus cidadãos-usuários atuais e potenciais e os } \\
\text { classificá-los por tipos ou grupos. }\end{array}$ \\
\hline 16 & $\begin{array}{l}\text { A organização divulga seus serviços e ações aos seus usuários atuais e potenciais e à } \\
\text { sociedade. }\end{array}$ \\
\hline 21 & A organização orienta e estimula a sociedade a controlar seus resultados institucionais. \\
\hline 25 & A organização define e prioriza as informações comparativas de que necessita. \\
\hline 26 & $\begin{array}{l}\text { A organização assegura que o conhecimento esteja alinhado com suas estratégias e seja } \\
\text { compartilhado. }\end{array}$ \\
\hline 27 & É feita a avaliação da implementação de inovações ou melhorias das práticas de gestão. \\
\hline 28 & É feita a avaliação dos padrões de trabalho relativos à gestão das informações. \\
\hline 32 & $\begin{array}{l}\text { As necessidades de educação e capacitação são identificadas e definidas considerando } \\
\text { as estratégias da organização. }\end{array}$ \\
\hline 33 & $\begin{array}{l}\text { As necessidades de educação e capacitação são identificadas e definidas considerando } \\
\text { a melhoria do desempenho das pessoas. }\end{array}$ \\
\hline 34 & $\begin{array}{l}\text { As necessidades de educação e capacitação são identificadas e definidas considerando } \\
\text { o crescimento individual das pessoas. }\end{array}$ \\
\hline 39 & É feita a avaliação da implementação de melhorias das práticas de gestão. \\
\hline 43 & $\begin{array}{l}\text { A gestão orçamentária e financeira é utilizada para suportar as estratégias e os planos da } \\
\text { organização. }\end{array}$ \\
\hline 48 & $\begin{array}{l}\text { São utilizados indicadores relativos à conservação do patrimônio e arrecadação de } \\
\text { receitas. }\end{array}$ \\
\hline 52 & evidenciam decréscimo nos serviços e produtos. \\
\hline
\end{tabular}

Quadro 3: Assertivas com índices de assimetria, igual ou menor a 0,15

Fonte: Elaborado pelos autores 
Outras assertivas apresentaram baixa assimetria, pois o índice de assimetria ficou entre 0,15 e 1 , e são distribuições moderadamente assimétricas. O Quadro 4 mostra quais são:

\begin{tabular}{|c|c|}
\hline \multicolumn{2}{|r|}{ Assertivas } \\
\hline 1 & $\begin{array}{l}\text { As decisões tomadas pela alta administração são comunicadas para as partes interessa- } \\
\text { das pertinentes. }\end{array}$ \\
\hline 2 & $\begin{array}{l}\text { As implantações das ações decorrentes destas decisões são acompanhadas pela alta } \\
\text { administração. }\end{array}$ \\
\hline 3 & A alta administração atua pessoalmente para garantir recursos para a infraestrutura. \\
\hline 4 & $\begin{array}{l}\text { Os valores e as diretrizes da administração pública são disseminados e internalizados } \\
\text { na organização. }\end{array}$ \\
\hline 6 & As implantações de inovações ou melhorias das práticas de gestão são feitas. \\
\hline 8 & $\begin{array}{l}\text { O desempenho global da organização é analisado considerando as necessidades de } \\
\text { todas as partes interessadas. }\end{array}$ \\
\hline 9 & A organização participa da formulação das políticas públicas em sua área de atuação. \\
\hline 11 & $\begin{array}{l}\text { As estratégias são desdobradas em planos de ação, para os diversos setores e unidades } \\
\text { da organização. }\end{array}$ \\
\hline 12 & $\begin{array}{l}\text { Os recursos alocados são suficientes para assegurar a implantação de todos os planos } \\
\text { de ação estabelecidos. }\end{array}$ \\
\hline 14 & $\begin{array}{l}\text { Os indicadores de desempenho e as metas estratégicas são adequados e previamente } \\
\text { comunicados às partes interessadas. }\end{array}$ \\
\hline 17 & São disponibilizados canais de acesso para solicitar assistência. \\
\hline 18 & São disponibilizados canais de acesso para solicitar esclarecimentos \\
\hline 19 & São disponibilizados canais de acesso para sugestões e reclamações. \\
\hline 20 & $\begin{array}{l}\text { A organização divulga padrões de qualidade no atendimento aos usuários de seus } \\
\text { serviços. }\end{array}$ \\
\hline 22 & $\begin{array}{l}\text { A organização promove a responsabilidade pública das pessoas no cumprimento de } \\
\text { seu papel de agente público, estimulando os valores e o comportamento ético. }\end{array}$ \\
\hline 23 & $\begin{array}{l}\text { As principais informações da organização são obtidas levando-se em conta as necessi- } \\
\text { dades de seus usuários. }\end{array}$ \\
\hline 24 & As informações são disponibilizadas a seus usuários com acesso rápido e fácil. \\
\hline 29 & $\begin{array}{l}\text { A organização assegura que a gestão do conhecimento seja utilizada para melhorar seus } \\
\text { produtos e serviços. }\end{array}$ \\
\hline 30 & interlocução e negociação estão definidos e pertinentes. \\
\hline
\end{tabular}

Quadro 4: Assertivas com índices de assimetria entre 0,15 e 1

Fonte: Elaborado pelos autores 


\begin{tabular}{|c|c|}
\hline \multicolumn{2}{|r|}{ Assertivas } \\
\hline 31 & $\begin{array}{l}\text { Os cargos e funções são preenchidos de acordo com as características e habilidades } \\
\text { necessárias. }\end{array}$ \\
\hline 35 & O orçamento existente para os planos de educação e capacitação é adequado. \\
\hline 36 & $\begin{array}{l}\text { O ambiente organizacional é seguro e saudável, considerando-se a ergonomia, saúde e } \\
\text { bem-estar das pessoas. }\end{array}$ \\
\hline 37 & A organização mede e avalia o bem estar, a satisfação e a motivação das pessoas. \\
\hline 38 & $\begin{array}{l}\text { Os custos associados aos projetos finalísticos são otimizados e compatíveis às necessi- } \\
\text { dades. }\end{array}$ \\
\hline 39 & É feita a avaliação da implementação de melhorias das práticas de gestão. \\
\hline 42 & $\begin{array}{l}\text { O processo de compras de bens materiais e de serviços é realizado levando-se em } \\
\text { consideração as necessidades internas da organização. }\end{array}$ \\
\hline 44 & As operações da organização são acompanhadas em termos orçamentários e financeiros. \\
\hline 45 & Os indicadores de satisfação dos usuários são mensurados e analisados. \\
\hline 46 & Os indicadores relativos à interação com a sociedade são mensurados e analisados. \\
\hline 47 & São utilizados indicadores de aplicação dos recursos orçamentários e financeiros. \\
\hline 49 & Os indicadores evidenciam melhorias nos sistemas de trabalho. \\
\hline 51 & Os indicadores evidenciam melhorias no processo de suprimentos. \\
\hline 53 & Os indicadores evidenciam melhorias nas práticas de gestão. \\
\hline
\end{tabular}

Quadro 4: Assertivas com índices de assimetria entre 0,15 e 1

Fonte: Elaborado pelos autores

A assertiva "a gestão do processo de compras de bens materiais e de serviços é realizada em conformidade com a legislação de compras, contratos e convênios" apresentou forte índice de assimetria, maior do que 1 . Possui uma assimetria de 1,141 com média de 3,45, moda e mediana igual a 4 . Nesse caso, a curva de frequência é assimétrica à esquerda com deformação negativa. Cabe ressaltar que o valor médio para todas as variáveis é 2,5, sendo o valor mínimo 1 , e o valor máximo 4 . Logo, esse resultado reflete forte aceitação do quesito analisado, pois apresenta os maiores valores para média, mediana e moda.

Ao analisar as frequências e os histogramas das variáveis com a inserção da curva normal, constatou-se a percepção do corpo permanente de militares da Escola Preparatória de Cadetes do Exército em relação aos critérios do Programa de qualidade do Governo Federal. Com relação ao critério liderança, o Quadro 5 apresenta a percepção dos pesquisados: 


\begin{tabular}{|c|c|c|c|c|c|c|c|c|}
\hline Assertiva & 1 & 2 & 3 & 4 & 5 & 6 & 7 & 8 \\
\hline Porcentagem (\%) & 82,5 & 74,4 & 67,5 & 75,6 & 51,3 & 51,3 & 55,4 & 43,3 \\
\hline
\end{tabular}

Quadro 5: Percepção em relação ao critério liderança

Fonte: Elaborado pelos autores

Constata-se que, das oito assertivas relacionadas ao critério liderança, em sete existe uma percepção positiva maior do que a negativa. Apenas a assertiva 8 teve uma percepção negativa maior do que a positiva. Do total de respostas, 66,67\% foram positivas. Logo, os militares da EsPCEx avaliam positivamente os aspectos da gestão relacionados à liderança.

Com relação ao critério estratégias e planos, o Quadro 6 apresenta a percepção dos pesquisados:

\begin{tabular}{|c|c|c|c|c|c|c|}
\hline Assertiva & 9 & 10 & 11 & 12 & 13 & 14 \\
\hline Porcentagem (\%) & 48,7 & 62,1 & 63,5 & 21,6 & 36,5 & 35,1 \\
\hline
\end{tabular}

Quadro 6: Percepção em relação ao critério estratégias e planos Fonte: Elaborado pelos autores

Constata-se que das seis assertivas relacionadas ao critério estratégias e planos, em quatro existe uma percepção negativa. Apenas as assertivas $10 e$ 11 tiveram uma percepção positiva maior do que a negativa. Do total de respostas, 55,41\% foram negativas. Logo, os militares da EsPCEx avaliam negativamente os aspectos da gestão relacionados à estratégia e aos planos.

Com relação ao terceiro critério, cidadãos e sociedade, o Quadro 7 apresenta a percepção dos pesquisados:

\begin{tabular}{|c|c|c|c|c|c|c|c|}
\hline Assertiva & 15 & 16 & 17 & 18 & 19 & 20 & 21 \\
\hline Porcentagem (\%) & 63,5 & 21,6 & 36,5 & 35,1 & 45,9 & 50 & 73 \\
\hline
\end{tabular}

Quadro 7: Percepção em relação ao critério cidadãos e sociedade Fonte: Elaborado pelos autores

Constata-se que, das sete assertivas relacionadas ao critério cidadãos e sociedade, em duas existem uma percepção positiva maior do que a negativa. Há quatro assertivas com percepção negativa maior do que a positiva $e$ uma com percepção empatada. Do total de respostas, $52,9 \%$ foram positi- 
vas. Logo, os militares da EsPCEx avaliam positivamente os aspectos da gestão relacionados ao cidadão e à sociedade.

Com relação ao critério informação e conhecimento, o Quadro 8 apresenta a percepção dos pesquisados:

\begin{tabular}{|c|c|c|c|c|c|c|c|}
\hline Assertiva & 22 & 23 & 24 & 25 & 26 & 27 & 28 \\
\hline Porcentagem (\%) & 70,3 & 50 & 64,9 & 55,4 & 51,4 & 48,6 & 45,9 \\
\hline
\end{tabular}

Quadro 8: Percepção em relação ao critério informação e conhecimento Fonte: Elaborado pelos autores

Constata-se que das sete assertivas relacionadas ao critério informação e conhecimento, em quatro existe uma percepção positiva maior do que a negativa. Existem duas assertivas com percepção negativa maior do que a positiva e uma com percepção empatada. Do total de respostas, 55,21\% foram positivas. Logo, os militares da EsPCEx avaliam positivamente os aspectos da gestão relacionados à informação e ao conhecimento.

Com relação ao quinto critério, sistemas de trabalho, o Quadro 9 apresenta a percepção dos pesquisados:

\begin{tabular}{|c|c|c|c|c|c|c|c|c|}
\hline Assertiva & 29 & 30 & 31 & 32 & 33 & 34 & 35 & 36 \\
\hline Porcentagem (\%) & 50 & 52,7 & 33,8 & 52,7 & 48,6 & 48,6 & 32 & 64,9 \\
\hline
\end{tabular}

Quadro 9: Percepção em relação ao critério sistemas de trabalho Fonte: Elaborado pelos autores

Constata-se que das oito assertivas relacionadas ao critério sistemas de trabalho, em três existem percepções positivas maiores do que as negativas. Há quatro assertivas com percepções negativas maiores do que as positivas e uma com percepção empatada. Do total de respostas, 52,03\% foram negativas Logo, os militares da EsPCEx avaliaram negativamente os aspectos da gestão relacionados a sistemas de trabalho.

Com relação ao critério processos, o Quadro 10 apresenta a percepção dos pesquisados: 


\begin{tabular}{|c|c|c|c|c|c|c|c|c|}
\hline Assertiva & 37 & 38 & 39 & 40 & 41 & 42 & 43 & 44 \\
\hline Porcentagem (\%) & 29,7 & 40,5 & 44,6 & 45,9 & 89,2 & 73 & 70,3 & 81,1 \\
\hline
\end{tabular}

Quadro 10: Percepção em relação ao critério processos Fonte: Elaborado pelos autores

Constata-se que das oito assertivas relacionadas ao critério processos, existem quatro assertivas com percepções negativas maiores do que as positivas e quatro com percepções positivas maiores do que as negativas. Do total de respostas, 59,29\% foram positivas. Logo, os militares da EsPCEx avaliaram positivamente os aspectos da gestão relacionados a processos.

Com relação ao critério resultados, o Quadro 11 apresenta a percepção dos pesquisados:

\begin{tabular}{|c|c|c|c|c|c|c|c|c|c|}
\hline Assertiva & 45 & 46 & 47 & 48 & 49 & 50 & 51 & 52 & 53 \\
\hline Porcentagem (\%) & 41,9 & 43,2 & 66,2 & 54,1 & 39,8 & 64,9 & 41,9 & 60,8 & 48,6 \\
\hline
\end{tabular}

Quadro 11: Percepção em relação ao critério resultados

Fonte: Elaborado pelos autores

Constata-se que das nove assertivas relacionadas ao critério resultados, há uma percepção negativa maior do que a positiva. Existem cinco assertivas, com percepções negativas maiores do que as positivas e quatro com percepções positivas maiores do que as negativas. Do total de respostas, 53,75\% foram negativas. Logo, os militares da EsPCEx avaliam negativamente os aspectos da gestão relacionados a resultados.

\section{Considerações Finais}

A hipótese de avaliação positiva pelo corpo permanente de militares da EsPCEx, com relação à implantação do Programa de Excelência Gerencial do Exército Brasileiro (PEG), medida através dos sete critérios da qualidade do Programa da Qualidade do Governo Federal, foi comprovada.

O resultado relativo à avaliação do corpo permanente foi positivo, pois dos sete critérios analisados de forma agrupada em quatro, as avaliações 
positivas foram maiores do que as negativas (critérios $1,3,4,6$ ) e em três delas, as avaliações negativas foram maiores do que as positivas (critérios 2 , 5 e 7).

Quando analisadas de forma individual, a quantidade de assertivas avaliadas positivamente também supera as negativas. Como são 53 assertivas respondidas por 74 militares, temos um total de 3.922. Desse total, foram avaliadas de forma positiva, ou seja, com resposta três (muitas vezes) ou quatro (sempre), um total de 2.072 ou $52,83 \%$.

O critério melhor avaliado quando visto de forma agrupada foi o critério liderança, pois das oito assertivas analisadas, sete, foram de forma positiva, sendo que das 592 , foram 387 positivas ou $65,37 \%$ do total. As assertivas mais bem avaliadas foram 41, 42 e 43 do critério processos e relacionadas a compras e à gestão econômico-financeira, de um total de 222, foram positivas 178 ou $80,18 \%$. A assertiva com pior avaliação individual foi a 12 , (os recursos alocados são suficientes para assegurar a implantação de todos os planos de ação estabelecidos), do total de 74, 78,4\% foram respondidas de forma negativa, ou seja, com respostas um (nunca) ou dois (raramente).

Tem-se, assim, um instrumento criado especificamente para a organização pesquisada, que se mostrou eficaz na obtenção da percepção dos participantes do programa de qualidade e pode ser adaptado para outras organizações.

Por fim, cabe destacar a questão de programas de qualidade em órgãos públicos, em especial os militares. A pesquisa mostrou que é possível sua utilização em órgãos públicos, como é o caso da EsPCEx, e que os participantes posicionam-se criticamente diante do programa, mesmo em ambientes militares, o que torna possível questionar dois dos mitos mais presentes quando se trata de programas de qualidade. 


\section{Evaluation of the Management Excellency Program: the Perception of the Military of the Permanent Corp of the Preparatory School of Cadets of the Brazilian Army}

\section{Abstract}

This paper discusses the implementation of the Management Excellence Program of the Brazilian Army (PEG-EB) in the Preparatory School Army Cadets (EsPCEx) identify the importance of the program and show the perception of this permanent implantation in the body of officers and men. The military presented their perceptions on the program and its implementation across the seven quality criteria Quality Program of the Federal Government (PQGF). We administered a survey instrument with 53 assertions, referring to the criteria adopted by the PEG-EB, the 175 soldiers belong to the complementary Officer (QCO) and Technical Services Temporary (STT) of EsPCEx with a Likert scale, graded zero to four. The results were tabulated with multivariate analysis, performed using a statistical package (SPSS) and shows the participants' perception of the quality program for each of the criteria adopted by the PEG-EB.

Key words: Evaluation of management. Program Management Excellence. Preparatory School of the Brazilian Army Cadets.

\section{Referências}

ARNOLD, Kenneth L. O guia gerencial para o ISO 9000. Rio de Janeiro: Campus, 1995..

BRASIL - Ministério do Planejamento, Orçamento e Gestão. Avaliação continuada da gestão pública. Brasília: SEGES, 2004.

. Gestão Pública: um programa voltado para o cidadão - documentos de referência do PQSP. Disponível em: <http:// www.pqsp.planejamento.gov.br/publicacoes.aspx?url=pub_opcoes.aspx > . Acesso em: 30 abr. 2008.

PETERSON, Robert A. A meta-analysis of Cronbach's Coefficient Alpha. Austin: IC2 Institute. Journal of consumer research, Chicago, 1994. 
ROBBI, Adelson. O Programa de excelência Gerencial na EsPCEx. Revista Pedagógica, EsPCEx, Campinas, n. 6, p. 10-11. 2004.

TOLEDO, Geraldo Luciano; OVALLE, Ivo Izidoro. Estatística básica. 2. ed. São Paulo: Atlas, 1987.

YIN, Robert K. Estudo de caso: planejamenteo e métodos. 3. ed. Porto Alegre: Bookman, 2005. 